\title{
Assessment of Sensory, Texture and Color Properties of Functional Pastilles Containing Licorice (Glycyrrhiza glabra L.)
}

Shadi Basiri *

\author{
Agricultural Engineering Research Department, Khorasan Razavi Agricultural and Natural Resources Research Center, AREEO, Mashhad, Iran
}

Background and Objectives: Medicinal pastilles are soft candies made (solidified) of thick liquids containing medicinal active ingredients. Licorice and its extracts are within the most important herbal plants used in various food industries and confectionaries. The substance is effective against diseases such as bronchitis and gastric ulcers.

Materials and Methods: In this study, effects of agar as a hydrocolloid and major active constituent of licorice (glycyrrhetinic acid) were studied on sensory attributes, texture properties and color indicators of fruit pastilles. Agar at three levels of 1,2 and 3\% and glycyrrhetinic acid at three levels of $0.1,0.5$ and $1 \%$ were used. Sensory attributes (taste, odor, firmness, elasticity, degree of adhesion and total acceptance), texture properties (stiffness, cohesiveness, gumminess and chewiness) and color indicators $\left(L^{*} a^{*} b^{*}\right)$ were assessed.

Results: Results showed that with increasing agar, brightness, redness and yellowness of the samples increased. By increasing agar, stiffness, cohesiveness, gumminess and chewiness of the samples increased as well. Organoleptic results showed that sensory properties of the samples were satisfying. Samples containing $3 \%$ agar and $1 \%$ glycyrrhetinic acid included the highest stiffness $(18555.5 \mathrm{~N} / \mathrm{m})$, cohesiveness $(0.48)$, gumminess $(7.6 \mathrm{~N})$ and chewiness $(0.026 \mathrm{Nm})$. Pastilles with $2 \%$ agar and $0.5 \%$ glycyrrhizin acid were the best products. Their stiffness, cohesiveness, chewiness and gumminess were minimal with good color and sensory properties.

Conclusions: With the production of these pastilles, it is possible to use the unique properties of licorice.

Keywords: Glycyrrhetinic acid, Medicinal pastilles, Texture properties, Sensory characteristics

\section{Introduction}

Recently, nutrition and its relationships to health have increasingly been interested by the people because food quality is important. Gummy candies contain a large group of confectionery products such as jellies and pastilles. Desirable textures can be created using gelling agents such as pectin, agar and especially gelatin. The substance components include various hydrocolloids, flavors, edible colors, sweeteners, edible acids, medicinal compounds and essences, which are gradually released by chewing in the mouth. Depending on the type and quantity of these compounds, dissolution rate of the product in the mouth varies (1). Fruit pastilles are novel products derived from fruits with several nutritional values. The major base of these products is puree or fruit concentrate. Pastilles have a long shelf life because of their decreased water activity. Production of such products on commercial scales help avoid fruit wastes and use their nutritional values such as minerals, vitamins and fibers as well as their optimum tastes and energy contents. Pastilles can be used by various age groups, especially children, pregnant women and athletes (2). Nowadays, common pastilles in the market are made from various sweeteners, thickeners, artificial dyes and other synthetic additives with low nutrition values (2). Sweeteners are effective in improving product texture, volume and taste (3). It is important to choose appropriate sweeteners to preserve the quality of products such as replacing sucrose with no alteration or loss in the product quality during the storage. Use of sweet fruit concentrates such as grapes, dates, berries and apples with Brix 65 as a natural sweetener includes several advantages. These can replace sucrose, creating good sensory properties, higher sweetening powers $(20 \%)$, lower calories $(25 \%)$, lower glycemic indices, high phenolic compounds and high antioxidant activities (4).

In this study, apple concentrate was used as a sweetener with the main basis of the fruit pastille formulation. 
Production of fruit pastilles with low water, viscosity and aqueous activity affects release of flavoring compounds (5). Type and concentration of the hydrocolloids used in preparation of pastilles include various effects on texture and sensory properties of the product (6). Hydrocolloids are a diverse group of carbohydrate long chain polymers (gums) and protein hydrocolloids (gelatins). Hydrocolloids include a wide array of functional properties in foods including thickening, gelling, emulsifying, stabilization and coating. Hydrocolloids are water-soluble compounds used in several processed foods as thickeners or gels (7). Hydrocolloid mixtures with synergistic interactions are important food additives. They include increasing uses in several food products as thickening and gelling agents (8, $9)$. By several studies on using more than one hydrocolloid in food formulations, optimum physical structures can be achieved (10). Recently, polysaccharide-protein compounds have interestingly been investigated by the researches and useful synergistic effects of these compounds have been assessed (11).

Roles and characteristics of the hydrocolloids used in this study are explained briefly. Gelatin is one of the hydrocolloids used in foods, especially pastilles. Gelatin is a heterogeneous mixture of high molecular-weight water soluble proteins derived from collagen hydrolysis (12). No hydrocolloids can replace gelatin including its whole properties (13). Gelatin is used in more than $95 \%$ of synthetic pastille formulations. There is less than $10 \%$ gelatin in each formula (14). Guar gum includes the ability to maintain high water contents due to its hydrophilic structure, which increasingly induces water absorption capacity of the final products (15). Guar gum can be used in food formulations due to its functional properties as a stabilizer and preservation of moisture contents of the products (16). Agar and its ability to form food gels have been used since several years ago (17). In a recent study in 2012, mixtures of agar and other hydrocolloids were used in fruit jelly products (18). Use of agar with other hydrocolloids in preparation of jelly products can create desirable and highly elastic tissues (11, 18). Gum tragacanth has been well accepted and approved as a food additive (19). The gum includes individual differences and unique functional characteristics (20, 21). Recently, use of medicinal plants and their active ingredients in preparation of chocolates, candies and other snacks has become common. In this study, an active ingredient of licorice was used. This substance is desirable for people with digestive disorders. Consumption of licorice (more than $2 \mathrm{mg} / \mathrm{kg} /$ day of pure glycyrrhizinic acid as a licorice component) may result in adverse effects such as hypokalemia, increased blood pressure and muscle weakness. The most important sweet ingredient of licorice is glycyrrhizinic acid, which is 50 times sweeter than sugar. The acid content varies with environmental conditions and plant species. The major use of this substance is sweetening of the food products. There is the taste of sweet extract in sweet snacks such as candies. The most important property of licorice includes its effects on digestive system. Licorice decreases gastric acid and bloating and can be used to relieve spasms and inflammations in digestive system. The compound anti-inflammatory, antimicrobial and antioxidant properties have been demonstrated.

Consumption of more than $5 \mathrm{~g}$ a day of licorice can cause metabolism disorder, raise blood pressure and gain weight. Consumption of tragacanth gum with licorice can make balances in properties of licorice. The aim of this study was to produce fruit pastilles containing licorice effective compounds and assess sensory, color and textural properties of the final products. Fruit pastilles with licorice are useful (functional) products. The advantages include apple concentrate contents instead of synthetic sucrose sweetener; no colors or artificial flavors in the formulation; and medicinal properties of the licorice.

\section{Materials and Methods}

Materials: The apple concentrate was purchased from Shahdiran Fruit Juice Factory, Mashhad, Iran. Glycyrrhizinic acid powder was provided by Zagros, Kermanshah, Iran. Gelatin, agar, tragacanth gum, guar, glucose powder and citric acid powder were purchased from Merck, Germany.

Pastille preparation: The apple concentrate included a brix of 70 and $\mathrm{pH}$ of 3.76. Constant components in the pastille preparation formulations included apple concentrate $(100 \mathrm{~g})$, gelatin $(5 \%)$, glucose powder $(4 \%)$, tragacanth gum $(2 \%)$, guar $(0.5 \%)$ and $2 \mathrm{ml}$ of citric acid $(40 \% \mathrm{w} / \mathrm{v})$ to improve the taste and adjust $\mathrm{pH}$ of the samples. Variable components in the formulations included agar (1, 2 and 3\%) and glycyrrhizinic acid powder (0.1, 0.5 and $1 \%)$. The container of apple concentrate sample was transferred into water bath $\left(80{ }^{\circ} \mathrm{C}\right)$ to distribute heat uniformly in the sample. Stirring was carried out permanently. Agar and gelatin solutions were added to the formulation, respectively. The rest of the materials were added to the sample after mixing with the glucose powder to prevent agglomeration. The prepared mixture was added to the mold and stored at $2-4{ }^{\circ} \mathrm{C}$ for $4 \mathrm{~h}$ to complete the hydration process and form the texture. These were stored in ambient air for a week. During this time, samples turned upside down to dry their texture. In this study, nine samples of fruit pastilles with licorice were produced (Table 1). 
Shadi Basiri: Functional pastille containing Licorice

Table 1. Quantities of various compounds in pastille samples

\begin{tabular}{|c|c|c|c|c|c|c|c|c|}
\hline Sample & $\begin{array}{c}\text { Apple } \\
\text { Concentrate (gr) }\end{array}$ & $\begin{array}{c}\text { Agar } \\
(\%)\end{array}$ & $\begin{array}{c}\text { Glycyrrhizinic Acid } \\
(\%)\end{array}$ & $\begin{array}{c}\text { Glucose Powder } \\
(\%)\end{array}$ & $\begin{array}{l}\text { Guar } \\
(\%)\end{array}$ & $\begin{array}{c}\text { Tragacanth } \\
\text { Gum }(\%)\end{array}$ & $\begin{array}{l}\text { Gelatin } \\
(\%)\end{array}$ & $\begin{array}{c}\text { Citric } \\
\text { Acid }(\mathrm{ml})\end{array}$ \\
\hline 1 & 100 & 1 & 0.1 & 4 & 0.5 & 2 & 5 & 2 \\
\hline 2 & 100 & 2 & 0.1 & 4 & 0.5 & 2 & 5 & 2 \\
\hline 3 & 100 & 3 & 0.1 & 4 & 0.5 & 2 & 5 & 2 \\
\hline 4 & 100 & 1 & 0.5 & 4 & 0.5 & 2 & 5 & 2 \\
\hline 5 & 100 & 2 & 0.5 & 4 & 0.5 & 2 & 5 & 2 \\
\hline 6 & 100 & 3 & 0.5 & 4 & 0.5 & 2 & 5 & 2 \\
\hline 7 & 100 & 1 & 1 & 4 & 0.5 & 2 & 5 & 2 \\
\hline 8 & 100 & 2 & 1 & 4 & 0.5 & 2 & 5 & 2 \\
\hline 9 & 100 & 3 & 1 & 4 & 0.5 & 2 & 5 & 2 \\
\hline
\end{tabular}

\section{Physicochemical experiments}

pH: The pH meter (Hana, Portugal) was used.

Brix: This was carried out using table refractometery (Carlze, China).

Moisture: To assess the moisture contents, 3-5 $\mathrm{g}$ of samples were heated at $105{ }^{\circ} \mathrm{C}$ for $2.5 \mathrm{~h}$. After cooling in desiccator and weighing, moisture contents were calculated based on the wet weight (22).

Water Activity: To assess water activity, equal weights of each sample were completely crushed and transferred into special plastic plates. Water activity of the samples was assessed at $25{ }^{\circ} \mathrm{C}$ using Novasina Humidifier, UK.

Texture assessment: In this study, texture analyzer (Farnell QTS25 CNS, UK) equipped with a computer software was used to assess texture properties of the pastille samples. Pastille samples were rotated in two reciprocating cycles using round cylinder probes with a diameter of $5 \mathrm{~cm}$, probe speed of $1 \mathrm{~mm} / \mathrm{s}$, trigger force of $0.1 \mathrm{~N}$ and up to $40 \%$ of the initial sample height. Samples were compressed and then depressed. Texture properties from the force-deformation curve included Stiffness, maximum force required to compress the substance (equivalent to the maximum force at the compression stage); Cohesiveness, texture consistency. Cohesion connects the components of the matter. Tissues that are interconnected and their components are fully interconnected. It is the force that connects molecules in the substance; chewiness, gumminess of the texture resulted from hardness and cohesiveness (23). It is necessary to chew and paste samples to swallow (24); and Gumminess, a combination of hardness and cohesion, including the force needed to eat a semi-solid food.

Color $\left(L^{*} \boldsymbol{a}^{*} \boldsymbol{b}^{*}\right)$ indices: Color indices of the pastille samples were assessed using Hunter Lab Colorimeter (Hunter Color Flex Model, US). Color of the processed products were assessed and expressed as $\mathrm{L}^{*}$ (brightness), $\mathrm{a}^{*}$ (red) and $\mathrm{b}^{*}$ (yellow) indicators. In color assessment systems, $\mathrm{L}^{*}$ in the range of 0 (dark) to 100 (brightness), $a^{*}$ in the range of -120 (green) to +120 (red) and $b^{*}$ in the range of $-b$ (blue) to $+b$ (yellow) were reported (25).

Sensory assessment: Sensory properties of the samples were assessed by ten expert panelists. Five-point hedonic scale was used to assess the samples. In total, six sensory traits (taste, odor, firmness, elasticity, degree of adhesion and total acceptance) were assessed.

Statistical design: Data analysis was carried out using completely randomized factorial test with three replications. Agar at three levels (1, 2 and 3\%) and glycyrrhizinic acid at three levels $(0.1,0.5$ and $1 \%)$ were considered as independent variables. Minitab 2016 software (Minitab, USA) was used for the statistical analysis. Means were compared using Duncan's multiple range tests (MRT) at the significant level of 5\%.

\section{Results}

Physicochemical properties of glycyrrhizinic acid powder and final formulation samples are presented in Tables 2 and 3, respectively.

Table 2. Physicochemical properties of glycyrrhizinic acid powder

\begin{tabular}{lc}
\hline Property & Content $(\%)$ \\
\hline Purity of glycyrrhizinic acid & $5-8$ \\
Amount of starch and gum & $22-29$ \\
Total sugar content & $18-22$ \\
Moisture & $3-5$ \\
Insoluble in cold water & $0.6-2$ \\
Insoluble in warm water & $0.5-2.5$ \\
Ash & $6-8$ \\
Flavor & Normal \\
PH & $5.4-5.65$ \\
\hline Source: Certified by Zagros Liquor Corporation &
\end{tabular}


Table 3. Comparison of the mean effects of agar and glycyrrhizinic acid on physicochemical properties of the pastille samples

\begin{tabular}{cccccccc}
\hline Sample & Agar $(\%)$ & GA $(\%)$ & PH & Brix & $\mathrm{a}_{\mathrm{w}}$ & Moisture $(\%)$ \\
\hline 1 & 1 & 0.1 & $3.63 \pm(0.01) \mathrm{bc}$ & $64 \pm(1)$ & $\mathrm{bc}$ & $0.573 \pm(0.001) \mathrm{e}$ & $11.79 \pm(0.01) \mathrm{c}$ \\
2 & 2 & 0.1 & $3.61 \pm(0.01) \mathrm{c}$ & $63.7 \pm(0)$ & $\mathrm{c}$ & $0.573 \pm(0.001) \mathrm{e}$ & $11.83 \pm(0.3) \mathrm{c}$ \\
3 & 3 & 0.1 & $3.65 \pm(0.01) \mathrm{ab}$ & $65.5 \pm(0.1) \mathrm{a}$ & $0.611 \pm(0.001) \mathrm{c}$ & $14.2 \pm(0.194) \mathrm{ab}$ \\
4 & 1 & 0.5 & $3.66 \pm(0.01) \mathrm{ab}$ & $64.4 \pm(0.15) \mathrm{b}$ & $0.624 \pm(0.001) \mathrm{b}$ & $14.3 \pm(0.09) \mathrm{ab}$ \\
5 & 2 & 0.5 & $3.67 \pm(0.01) \mathrm{a}$ & $62.6 \pm(0.1) \mathrm{d}$ & $0.607 \pm(0.001) \mathrm{d}$ & $14.87 \pm(0.265) \mathrm{ab}$ \\
6 & 3 & 0.5 & $3.66 \pm(0.01) \mathrm{ab}$ & $65.3 \pm(0.1) \mathrm{a}$ & $0.636 \pm(0.001) \mathrm{a}$ & $15.13 \pm(1.143) \mathrm{a}$ \\
7 & 1 & 1 & $3.56 \pm(0.01) \mathrm{d}$ & $63.5 \pm(0.1 \mathrm{c}$ & $0.542 \pm(0.001) \mathrm{g}$ & $14.09 \pm(0.185) \mathrm{b}$ \\
8 & 2 & 1 & $3.64 \pm(0.01) \mathrm{b}$ & $64.4 \pm(0.1) \mathrm{b}$ & $0.549 \pm(0.001) \mathrm{f}$ & $14.2 \pm(0.272) \mathrm{ab}$ \\
9 & 3 & 1 & $3.60 \pm(0.01) \mathrm{c}$ & $62.7 \pm(0.1) \mathrm{d}$ & $0.541 \pm 0.001) \mathrm{g}$ & $13.68 \pm(0.335) \mathrm{b}$ \\
\hline
\end{tabular}

Note: Values in parenthesis are standard deviations;

Numbers with different letters in each column are statistically significant differences $(p<0.05)$.

GA: glycyrrhizinic acid

Sensory properties: Comparison of the means of pastille sensory parameters is shown in Table 4. Sensory characteristics showed that samples were not significantly different $(p>0.05)$.
Color parameters: The mean effects of agar and glycyrrhizinic acid on pastille color parameters are compared in Table 5.

Texture characteristics: The mean effects of agar and glycyrrhizinic acid on texture parameters of the pastille samples are compared in Table 6.

Table 4. Comparison of the mean of pastille sensory parameters

\begin{tabular}{|c|c|c|c|c|c|c|c|c|c|}
\hline Sample & Agar (\%) & GA (\%) & Tas & & Odor & firmness & Elasticity & Adhesion & Acceptance \\
\hline 1 & 1 & 0.1 & 4.2 & $\mathrm{a}$ & $3.8 \mathrm{a}$ & $4.4 \mathrm{a}$ & $4.4 \mathrm{a}$ & $4.2 \mathrm{a}$ & $4 \mathrm{a}$ \\
\hline 2 & 2 & 0.1 & 3.8 & $\mathrm{a}$ & $4 \quad \mathrm{a}$ & $4.6 \mathrm{a}$ & $4.6 \mathrm{a}$ & $4.4 \mathrm{a}$ & $4.4 \mathrm{a}$ \\
\hline 3 & 3 & 0.1 & 4 & $\mathrm{a}$ & $3.4 \mathrm{a}$ & $4 a$ & $3.6 \mathrm{a}$ & $4.2 \mathrm{a}$ & $3.8 \mathrm{a}$ \\
\hline 4 & 1 & 0.5 & 4.2 & $\mathrm{a}$ & $3.4 \mathrm{a}$ & 4 & $4 a$ & $3.8 \mathrm{a}$ & $4 \mathrm{a}$ \\
\hline 5 & 2 & 0.5 & 4 & $\mathrm{a}$ & $4 a$ & $4.2 \mathrm{a}$ & $4.4 \mathrm{a}$ & $4.4 \mathrm{a}$ & $4.2 \mathrm{a}$ \\
\hline 6 & 3 & 0.5 & 3.6 & $\mathrm{a}$ & $3.4 \mathrm{a}$ & $3.6 \mathrm{a}$ & $3.8 \mathrm{a}$ & $4.2 \mathrm{a}$ & $3.6 \mathrm{a}$ \\
\hline 7 & 1 & 1 & 3.4 & $\mathrm{a}$ & $3.6 \mathrm{a}$ & $4 a$ & $3.4 \mathrm{a}$ & $3.8 \mathrm{a}$ & $3.6 \mathrm{a}$ \\
\hline 8 & 2 & 1 & 3.2 & $\mathrm{a}$ & $3.4 \mathrm{a}$ & $3.8 \mathrm{a}$ & $4 a$ & $4 a$ & $3.6 \mathrm{a}$ \\
\hline 9 & 3 & 1 & 3.6 & $\mathrm{a}$ & $3.8 \mathrm{a}$ & $3.6 \mathrm{a}$ & $3.8 \mathrm{a}$ & $4.4 \mathrm{a}$ & $3.8 \mathrm{a}$ \\
\hline
\end{tabular}

Numbers with same letters in each column are not statistically significant differences $(\mathrm{P}>0.05)$.

GA: glycyrrhizinic acid

Table 5. Comparison of the mean effects of agar and glycyrrhizinic acid on color indices $\left(L^{*} a^{*} b^{*}\right)$ of the pastille samples

\begin{tabular}{|c|c|c|c|c|c|}
\hline sample & Agar (\%) & glycyrrhizinic acid (\%) & $L^{*}$ & $a^{*}$ & $b^{*}$ \\
\hline 1 & 1 & 0.1 & $15.04 \pm(0.16) \mathrm{cd}$ & $12.61 \pm(0.02) \quad b$ & $11.31 \pm(0.19) \mathrm{d}$ \\
\hline 2 & 2 & 0.1 & $14.32 \pm(0.20) \mathrm{e}$ & $13.37 \pm(0.18) \quad \mathrm{a}$ & $13.08 \pm(0.41) b$ \\
\hline 3 & 3 & 0.1 & $13.16 \pm(0.12) \mathrm{f}$ & $12.84 \pm(0.6) \quad a b$ & $13.22 \pm(0.47) b$ \\
\hline 4 & 1 & 0.5 & $13.15 \pm(0.20) \mathrm{f}$ & $1.58 \pm(0.07) \quad \mathrm{c}$ & $14.09 \pm(0.05) \mathrm{a}$ \\
\hline 5 & 2 & 0.5 & $15.47 \pm(0.21) \quad \mathrm{c}$ & $9.94 \pm(0.07 \mathrm{e}$ & $9.78 \pm(0.10) \quad \mathrm{e}$ \\
\hline 6 & 3 & 0.5 & $17.31 \pm(0.42) \quad a$ & $10.47 \pm(0.28) \mathrm{d}$ & $12.6 \pm(0.20)$ \\
\hline 7 & 1 & 1 & $14.77 \pm(0.17) \mathrm{de}$ & $6.90 \pm(0.17) \quad \mathrm{g}$ & $6.51 \pm(0.10) \quad \mathrm{g}$ \\
\hline 8 & 2 & 1 & $16.82 \pm(0.03) \mathrm{ab}$ & $8.07 \pm(0.06)$ & $11.39 \pm(0.22) \mathrm{d}$ \\
\hline 9 & 3 & 1 & $16.56 \pm(0.43) \quad b$ & $7.68 \pm(0.24)$ & $7.05 \pm(0.36) \quad f$ \\
\hline
\end{tabular}

Note: Values in parenthesis are standard deviations;

Numbers in column followed by the same letter are not significantly different $(p>0.05)$.

Table 6. Comparison of the mean effects of agar and glycyrrhizinic acid on textural properties of the pastille samples

\begin{tabular}{|c|c|c|c|c|c|}
\hline sample & Stiffness (N/m) & & cohesiveness & Chewiness (Nm) & Gumminess (N) \\
\hline 1 & $8678.66 \pm(348)$ & $\mathrm{b}$ & $0.541 \pm(0.039) \mathrm{ab}$ & $0.017 \pm(0.00)$ bc & $4.32 \pm(0.13) b c$ \\
\hline 2 & $10526.49 \pm(1986)$ & $\mathrm{b}$ & $0.547 \pm(0.013) \mathrm{ab}$ & $0.019 \pm(0.00) \mathrm{b}$ & $4.88 \pm(0.66) b$ \\
\hline 3 & $8855.316 \pm(572)$ & $\mathrm{b}$ & $0.497 \pm(0.016) \mathrm{ab}$ & $0.016 \pm(0.00) \mathrm{bc}$ & $4.23 \pm(0.12) b c$ \\
\hline 4 & $7029.439 \pm(1799)$ & b & $0.560 \pm(0.011) \mathrm{a}$ & $0.013 \pm(0.00) \mathrm{c}$ & $3.62 \pm(0.65) b c$ \\
\hline 5 & $7546.722 \pm(1658)$ & b & $0.471 \pm(0.022) b$ & $0.011 \pm(0.00) \mathrm{c}$ & $3.23 \pm(0.25) \mathrm{c}$ \\
\hline 6 & $8249.215 \pm(1064)$ & $b$ & $0.484 \pm(0.030) b$ & $0.011 \pm(0.00) \mathrm{c}$ & $3.25 \pm(0.59) \mathrm{c}$ \\
\hline 7 & $10024.2 \pm(1298)$ & $b$ & $0.507 \pm(0.008) a b$ & $0.016 \pm(0.00) \mathrm{bc}$ & $4.59 \pm(0.16) b c$ \\
\hline 8 & $9583.77 \pm(1814)$ & $\mathrm{b}$ & $0.485 \pm(0.072) \mathrm{ab}$ & $0.014 \pm(0.00) \mathrm{c}$ & $3.82 \pm(0.68) b c$ \\
\hline 9 & $18555.54 \pm(1947)$ & $\mathrm{a}$ & $0.486 \pm(0.038) \mathrm{ab}$ & $0.026 \pm(0.00) \mathrm{a}$ & $7.59 \pm(1.22) \mathrm{a}$ \\
\hline
\end{tabular}

Note: Values in parenthesis are standard deviations;

Numbers in column followed by the same letter are not significantly different $(p>0.05)$. 


\section{Discussion}

Based on the Table 3, moisture content and moisture retention of the pastille samples increased with increasing agar. When excess water from the sample texture prevented increases in hydrocolloids of the formulations, water activity of the samples increased. Khalilian et al. (2011) achieved similar results by adding xanthan gum to cantaloupe pastille formulations (26).

Color parameters: Color is one of the most important factors in the quality of products such as jam, marmalade, sauce and paste from fruits, which is affected by the fruit type and processing method (heat and heating time) of the products (27). Food processing such as drying, concentrating, baking and formulating can significantly affect color (2). Analysis of variance from effects of agar and glycyrrhizinic acid on color indices $\left(L^{*} a^{*} b^{*}\right)$ of the pastille samples were significant. Based on Table $5, L^{*}$ index (color brightness) increased as the agar concentration in the samples increased as well as the color indices of $a^{*}$ (red color) and $b^{*}$ (yellow color) of the samples. Increasing agar in formulations increased moisture absorbed by the samples. This might increase brightness of the pastille samples. A study by Saha and Bhattacharya (2010) showed that increases agar concentrations in Kiwi formulation pastilles increased transparency and brightness of the samples (9). Khalilian et al., (2011) reported that increases in hydrocolloids of the cantaloupe pastille formulations significantly changed color index of $L^{*}$ (26). Increasing agar in the samples increased red color in the final products (increased index of $a^{*}$ ). These color changes were possibly due to the chemical reactions such as Millard reaction that caused brown color in foods with links to melatonin pigments. Maillard reactions in pastilles are possible due to the presence of reductive sugars and gelatin, resulting in the production of brown and dark pigments. Other factors affecting fruit pastille color include chemical reactions such as oxidation of pigments and changes in cis-trans isomers of the pigments. Various levels of consumed hydrocolloids can include increasing or decreasing effects on the reaction (28). Rahimi Dogahi et al. (2013) assessed the color parameters of pastilles produced from tomato. Results showed that tomato pastilles were susceptible to non-enzymatic browning reactions (29). Increasing carboxyl methyl cellulose hydrocolloids in samples may include resonant effects on the Millard browning reaction. The $b^{*}$ index was linked to the yellow color. Results showed that this parameter increased with increasing agar. A study reported that guar included direct effects on $b^{*}$ or yellowness of the samples. Naturally, guar includes protective effects on beta-carotene contents of the fruits; thus, it can affect yellowing rates of the pastilles containing agars (30).

Texture characteristics: Textural properties of foods are important in acceptance of foods by the consumers. The texture profile analysis has been used for decades as an appropriate method for the assessment of food textures. In a study by Lau et al. (2000), curve parameters were well correlated to sensory data (31). The mean effects of agar and glycyrrhizinic acid on texture parameters are compared in Table 6. Based on the data, the highest texture stiffness belonged to Sample 9. Other samples included no significant differences. Agar strengthened the texture and in combination with glycyrrhizinic acid increased the proportion of soluble solids, causing texture stiffness. In the present study, cohesiveness of the samples was assessed. Cohesiveness refers to how a food product compartments stay together after deformation. Cohesiveness of the pastille samples varied from 0.48 to 0.56 . No statistically significant differences were seen between the samples. The highest chewiness property was observed in Sample 9. This sample included the highest quantities of agar and glycyrrhizinic acid, which caused the highest chewiness interaction rate of agar and glycyrrhizinic acid. Other samples included no significant differences. Maghami kia et al. (2012) reported that replacement of grape concentrates with invert sugars in soy milk pastilles decreased the tissue cohesion. Gumminess refers to the food density that is resistant to chewing (32). Gumminess of the pastille treatments in this study ranged 3.2-7.6 g. Gumminess is a result of stiffness in cohesion and agar seems to play important roles in tissue stiffness and enhancement in gumminess. This is associated to the hydrophilic property and water absorption of the hydrocolloid compounds (24). The highest gumminess in samples belonged to Sample 9 while the other samples showed no significant differences.

\section{Conclusions}

In this study, various samples of pastilles containing licorice effective compound (glycyrrhizinic acid) were prepared. Various quantities of agar and glycyrrhizinic acid were used. Color, texture and sensory characteristics of the final products were assessed. In general, effects of the variables on sensory characteristics of the samples were not significant. Findings of the assessment of texture properties revealed that increasing agar contents in formulas increased stiffness, cohesiveness, gumminess and chewiness of the samples. Results of color assessment showed that by increasing levels of the variables, color indices of $\mathrm{L}^{*} \mathrm{a}^{*} \mathrm{~b}^{*}$ increased. Brightness, redness and yellowness of the samples increased. Pastilles with 2\% agar and $0.5 \%$ glycyrrhizin acid were the best pastilles. Their stiffness, cohesiveness, chewiness and gumminess were minimal with good sensory properties. By producing these pastilles, it is possible to use the unique properties of licorice.

\section{Financial disclosure}

The author declare no conflict of interest. 


\section{Funding/Support}

This study was financially supported by Khorasan Razavi Agricultural and Natural Resources Research Center.

\section{References}

1. Picconea P, Rastellib SL, Pittia P. Aroma release and sensory perception of fruit candies model systems. Procedia Food Science 2011; 1: 1509 - 1515.

2. Basiri S, Shahidi F. Investigation on the effects of different amounts of gelatin and guar on texture, organoleptic and color properties of white mulberry pastille. Iranian food science and technology research journal 2017; 13 (1): 1-13 [in Persian].

3. Fisker HO, Nissen V. Effect of gum base and bulk sweetener on release of specific component from fruit flavored chewing gum. Developments in Food Science 2006; 43: 429-432.

4. Mojaverian P, Raftani amiri Z, Shahiri Tabarestani H Optimization of ginger gummy confection formulation based on chicken feet and grape concentrate using response surface methodology (RSM). Journal of food science and technology 2018; 82 (15): 319-334 [in Persian].

5. Hansson A, Andersson J, Leufven A. The effect of sugars and pectin on flavor release from a soft drink-related model system. Food Chemistry 2001; 72: 363-368.

6. Mc Gorrin RJ, Leland JV editors. Flavor-food interactions, American Oil Chemical Society. Washington. DC.1996. p. 98108.

7. Lee KY, Shim J, Bae IY, Cha J, Park CS, Lee HG. Characterization of gellan/gelatin mixed solutions and gels. Lebensm. Wiss. Technol (LWT) 2003; 36: 795-802.

8. Moreira R, Chenlo F, Torres MD. Effect of chia (Sativa hispanica L.) and hudrocolloids on the rheology of gluten-free doughs based on chesnut flour. LWT-Food Science and Technology 2013; 50 (1): 160-166.

9. Saha D, Bhattacharya S. Hydrocolloids as thickening and gelling agents in food: a critical review. Journal of food science and technology 2010; 47 (6): 587-597.

10. Harris P, editor. Food Gels. Elsevier Applied Science, London, UK 1990. 8: 291-298.

11. Khazaii pool E, Shahidi F, Mortazavi A, Mohebi M. The effect of different levels of Spirulina Platensis micro-algae and agar and guar hydrocolloids on water activity, texture, color parameters and Overall acceptability of kiwi puree-based fruit pastille. Food Science and Technology 2015; 12 (48): 47-59 [in Persian].

12. Bhat R, Karim A. Ultraviolet irradiation improves gel strength of fish gelatin. Food Chemistry 2009; 113: 1160 -1164.

13. Hang IJ, Draget KI, Smidsord O. Physical and rheological properties of fish gelatin compare to mammalian gelatin. Food hydrocolloids 2004; 18: 203-213.

14. Kim Y. Development and characterization of gelatin films as active packaging layers. 2005. 65: 2-10.

15. Williams PA, Phillips GO. (2000). Hand book of hydrocolloid. Introduction to food hydrocolloids. Wood head Publishing Limited and CRC Press LLC. 2000.

16. Whistler RL, editor. Industrial gums, 2th ed. New York: Academic Press. 1973. p. 303 - 321.
17. Rezaii R, Shahidi F, Elahi M, Mohebi M, Nasiri Mahallati M. Analysis of plum pastille texture profile by sensory and instrumental methods and optimization of its formulation. Iranian food science and technology research journal 2012; 8 (1): 30-39 [in Persian].

18. Sadeghi F, Shahidi F, Koocheki A, Mohebi M. Almond pastille (Jel Mac) formulation based on sensory, textural properties, color and water activity. Journal of food science \& technology 2016; 12 (50): 196-207.

19. Phillips GO, Williams PA, editors. Handbook of hydrocolloids. 1 th ed. Cambridge, wood head publishing Ltd and Boca Raton, CRC Press LLC. 2000

20. Anderson D, Bridgeman $M$. The composition of the proteinaceous polysaccharides exuded by Astragalus microcephalus, A. Gummifer and A. Kurdicus -The sources of turkish gum tragacanth. Phytochemistry 1985; 24 (10): 2301 - 4.

21. Anderson D, Grant D. The chemical characterization of some Astragalus gum exudates. Food Hydrocolloids 1988; 2 (5): 41723.

22. Tsami E, Marinous DM. Water sorption isotherms of raisins, currant, figs, prunes and apricots. Journal of Food science 1990; 55: 1594- 1597.

23. Fiuzy B, Mazaheri M, Khazaii E. Formulation of concentrated date and whey concentrate gel and evaluation its physicochemical and sensory properties. Journal of Iranian Food Science and Technology Research 2015; 12 (1): 61-78 [in Persian].

24. Kealy T. Application of liquid and solid rheological technologies to the textural characterization of semi-solid food. Food Reserch International 2006; 39: 265-276.

25. Yildiz O, Alpaslan M. Rose Hip Marmalade, Food Technology Biotechnology 2012; 50 (1): 98-106.

26. Khalilian S, Shahidi F, Mohebi M, Sarmad M. The effect of different concentrations of pectin and xanthan on sensory properties and water activity of fruit pastille based on cantaloupe puree. Journal of Iranian Food Science and Technology Research 2011; 4 (7): 209-219 [in Persian].

27. Guine RPF, Joao Barroca M. Effect of drying treatments on texture and color of vegetables (pumpkin and green pepper). Food and bioproducts processing 2012; 90 (1): 58-63.

28. Hanssen M, Blennow A, Pedersen S. Gel texture and chain structure of amyl maltase-modified starches compared to gelatin. Food Hydrocolloids 2008; 22:1551-1566.

29. Rahimi dogahi P, Shahidi F, Bolorian S, Mohamadi Sani A. Evaluation on color parameters of tomato based pastille. 21 national congresses of food science and technology; 2013; Shiraz, Iran. [In Persian].

30. Sacks EJ, Francis DM. Genetic and environmental variation for tomato flesh color in a population of modern breeding lines, Journal of the American Society for Horticultural Science 2001; 126, 2: 221-226.

31. Lau M, Tang J, Paulson AT. Texture profile and turbidity of gellan / gelatin mixed gels. Journal food research international 2000; 33: 665-671.

32. Maghami kia H, Khalilian S, Mohammadi A. The possibility of using natural sweetener (grapes concentrate white and red) in the formulation of soy bean. The 21st congress of Iranian food science and technology; 2013; Shiraz, Iran. [In Persian]. 